\title{
Social Skills and Programs of Positive Discipline in School Environment - A Literature Review
}

\author{
Dr. Proc. Marta Bej
}

Doi:10.5901/mjss.2016.v7n2s1p84

\begin{abstract}
The current article is a literature review with the intention to examine the impact of different programs of Positive Discipline applied in school settings. The main focus is on providing a full panorama on several studies of PD applied to classrooms in different approaches and to understand how these programs are implemented on everyday academic life. A systematic literature search was carried out in order to explore current researchaddressing the implementation of PD programs and their effectiveness, in school settings. This literature review demonstrates that quality relationships with peers, teachers and parents make a big difference for young people, especially in those trying to build strong social skills. Students who perceive a sense of belonging and connectedness are less likely to engage in socially risky behaviors, and are more prone to academic success.Different studies show that by implementing this approach, positive results as reduced risk for aggressive behavior, decreased violence, positive school climate, youth behaviour, problem solving, and friendship building abilities, are the outcomes.
\end{abstract}

Keywords: Social skills; Positive Discipline; Adolescence; Classroom-meetings.

\section{Introduction}

Our social skills are critical to successful functioning in life. Managing to have good ones, is way more beneficial, because they enable us to know what to say, how and when to say it, and also how to behave in different social situations. As the adults know their importance in life, children learn how to improve them in their everyday journey through their behavior, social and family relationships. One of the best environments where children can learn how to possess good social skills is the school environment, and especially one that provides quality and safety. But, how can the school help a child to build these skills, and shape them into successful, contributing members of their community?

The aim of the present study is to conduct a literature review, including the theoretical approach and studies focusing on the implementation of the Positive Discipline techniques in school settings, and how such programs and techniques help children and teachers, build strong social skills and help prevent maladaptive behaviors. This study will add to the existing literature

According to Charles and Senter (2005), Positive Discipline is one of the best programs developed by Nelsen, Lott and Glenn (based on the theories of Alfred Adler and Rudolf Dreikus,1930), which can help teachers develop classrooms where students are taught the skills needed to respect and learn how to cooperate with each other. This program consists on helping students in perceiving themselves as capable, significant and in control of their lives, also developing skills of self-control, cooperation, and adaptability. But, it also helps the teachers to set a classroom climate where there is acceptance, respect, and encouragement. Teachers learn how to demonstrate caring by talking with students, showing personal interest in their achievements and facilitating the relationships by removing the existing barriers (Charles and Senter, 2005).

This is an educational approach which recognizes all aspects of children's learning and development and perceives them as interrelated. It enables us to respond to discipline issues positively, and prevent most discipline problems before they happen, by understanding the interrelationships among: individual development, learning and academic achievements, family relationships and by contribution to the community health (Durrant, 2010). This approach is holistic, inclusive, strengths-based, proactive, constructive and participatory. As Durrant (2010) noted, "Positive discipline emphasizes the teacher's role in building students' self-esteem and confidence, nurturing their independence, and fostering their sense of self-efficacy".

Teachers and parents can work in collaboration to encourage and nurture the development of social skills in children, and by doing so they can stimulate the growth of effective social skills, by providing the student with a range of learning experiences inside and outside the classroom (Bhargava, 2010). The greater benefits of social skills instruction is that it can improve both the academic and social functioning of individual students and improve the interpersonal climate of the classroom for all the students (Siperstein \&Richards, 2004). 


\section{Review of Literature}

Problems such as violence, vandalism, bullying, antisocial behaviour, poor development of pro-social skills (etc.), create an unsafe learning environment, and it may predict later maladjustment in children's life (Hawkins, Catalano \& Miller 1992). By trying to reduce the amount of these behaviours, longitudinal research points to large scale primary and secondary prevention models, as a way to influence positive school climate and youth behaviour (Luiselli, Putnam, Handler, Feinberg, 2005). Different researchers have identified that several interventions of Positive Discipline and other similar approaches have proven to be very effective in school intervention. The approaches based on social skills training, have promoted social competence by teaching students how to interact more effectively with peers and adults through enhanced conflict resolution, problem solving, and friendship building abilities, by reinforcing them positively, demonstrating these skills in vivo and expressing improved attitudes (Weissberg\& Greenberg,1997).

What this approach brings to the school environment is a "helping hand" for the student to feel connected, and to increase the sense of "belongingness", which is proven also to increase academic success and to decrease socially risky behavior (Battistich, 1999). The used interventions teach skills for social belonging, and increase the likelihood of succeeding at school and in the social environment (Battistich, 1999, Nelsen 1979). The Positive Discipline uses techniques that have been shown to have a positive impact on schools. A study of a school-wide implementation of classroom meetings in a lower income Sacramento elementary school over a four-year period showed that vandalism decreased (from 24 episodes in 2), suspensions decreased, and that the teachers reported great improvement classroom atmosphere, behavior, attitude and academic performances (Platt,1979; McVittie,2003). Also other studies performed with teachers and parents, using the education program and techniques of Positive Discipline, have proven to be very effective in changing the maladaptive behavior in students (Nelsen, 1979). Smaller studies examining specific Positive Discipline techniques have also shown positive results, even if the Positive Discipline intervention used was time-limited and very specific (Browning 2000, Potter 1999).

There are many published studies on parent education that support the PD (Positive Discipline) model of teaching group of parents through role plays and games, on how to change parenting practices. Very often teaching parents in groups has been shown to be more effective than individualized instruction (Goodson et al., 2001). A three-year study conducted by Nelsen (1979) included parents and teachers of students identified as having maladaptive behavior, in a 12-week Adlerian parenting study group. The behavior was evaluated at home and in the classroom before and after the intervention. Also another group of students, used as the comparison group, were identified using the same criteria at another school. According to the results significant changes were found when compared to analysis of behaviors in the comparison group of students (Nelsen, 1979; McVittie, 2003). In a small study, Stanley (1978) showed that when students and parents are taught Adlerian parenting skills together, the teens continued to advance in their moral development even the year after the class, and sometimes even later (McVittie, 2003).

Nelsen, Lott and Glenn (2000), have identified three perceptions and four skills that contribute to the benefits of Positive Discipline. These perceptions and skills are grouped in one category under the name of "The significant Seven". According to these, class meetings help students develop self-perceptions of personal capabilities, significance in primary relationships and personal power, which can lead to great success in life. Class meetings can also help students develop essential skills like the Intrapersonal ones: which helps to understand better the inner world of the individual, Interpersonal skills: to build the cooperation and communication between the individual and others around him, Strategic skills: to be flexible and responsible, and the Judgmental skills: which gives a better understanding and evaluating of the situations (Charles, Senter, 2005). Studies show that students who are taught social skills early in their school career have a reduced risk for aggressive behavior. When first grade teachers were taught a method of teaching kids how to cooperate and work in groups, the level of classroom aggression went down. The boys from those classrooms were much less likely to demonstrate aggressive behavior in middle school, when evaluated (Kellam, 1998). This finding is notable giving previous findings (Campbell, 1995) that behaviors noted in preschool are likely to persist into the later years (McVittie, 2003). However the data shows that several different programs and techniques that work to enhance school communities and academic success, and also intervening in a more interpersonal level, by accessing student's social skills, are successful when they are implemented well.

The most important way that this approach should be seen, is by taking into consideration its elements and the way that they are implemented. Firstly as Charles and Senter, (2005) noted: "The approach to discipline advocated by Nelsen, Lott and Glenn requires that teachers truly care about their students' welfare and that they should make such caring evident". They should try to learn new information for the students, by seeing them as individuals, encourage them to grow, and see mistakes as new opportunities to improve. Emmet et al., conducted a study in (1996) which showed that students who were part of the interventions in classroom meetings, reported that they learned how to trust each other, 
how to be safe, get to know their teachers, feel better about themselves, share common problems, understand and share feelings, learn appropriate behaviors and problem solving strategies (McVittie,2003).

In another study which evaluated the impacts of "The responsive classroom", which is based on "morning meetings", and setting clear guidelines for students, Elliot (1993) found that after one year, in comparison with a group of students in a non-intervention school, the intervention school students had increased significantly social skills, and decreased problem behaviors. Potter (1999) also conducted a similar study, in which the effects of class meetings were examined. The results included observed improvements in active listening, appreciation of others and positive view of the conflicts, respect, and also the sense of community. Another interesting study, as McVittie (2003) cited, was made by Zeeman and Martucci (1976), with 9 learning disabled pupils, 10 to 11 years old, who participated in open-ended class meetings, demonstrated increased verbal participation, decreased hyperactivity and diminished social isolation from regular class children (Zeeman, Martucci, 1976).

Esquivel also tried conducting similar studies, and reviewed the impact of Positive Discipline class meetings in her own classroom of 19 first grade students, and the results found positive impacts in the social skills training, and especially on three of the children with especially challenging needs (McVittie, 2003).

\section{Method}

\subsection{Search Strategy}

A systematic literature search was carried out in order to explore current research addressing the implementation of PD programs and their effectiveness, in school settings. The search was based in two key components: there should be a) a specific PD intervention technique, and b) an outcome evaluation. The following terms and text words were used: "positive discipline", "social skills", "classroom-meetings", "social competences", "parents/teachers-meetings", in combination with "intervention", "positive discipline techniques", "social skills training", and also combined with terms related to outcome research: "effect", "evaluation", "positive outcomes". The search was restricted to studies conducted in the English language, and focusing only on Positive Discipline programs.

\section{Conclusions}

The positive results that these studies show are based on the main goal that PD interventions try to accomplish, which is "focusing on the solution" (McVittie, 2006). According to this approach the behavior is motivated by the students who always seek a sense of belonging and significance in their social context. By fulfilling this sense of belongingness, and creating an ongoing relationship founded on mutual respect, student would be able to have the most influence on the behavior of others, and also to create a relationship, where each one of them is equally worthy of dignity and respect (McVittie, Chadsey, 2006). By doing so, students not only learn on how to improve their social skills, but also how to use them in different social situations, like responding to inappropriate behavior. As Chadsey, 2006 noted, the response to inappropriate behavior is done by: "Naming without shaming and blaming, focus on solutions, follow through, and addressing the belief behind the behavior" and also the response to dangerous and destructive behavior is not performed by censure, isolation and punishment, but by: "Clearly following through, without getting in the way of the student experiencing the consequence of their action" (McVittie, 2006).

Nelsen, Lott and Glenn (2000), provide a discipline program designed to help students accept responsibility and take positive control of their behavior. They say that punishment, rewards, and praise have no positive effect in developing self-directed people. They believe that each problem presents an opportunity for learning and that students learn very important life skills by helping each other find positive solutions to problems (Charles, Senter, 2005). This discipline depends most, on successful implementation of class meetings as an integral part of the instructional program. As shown by the studies presented above, that is, because the meetings make it possible to involve students in discussions about their behavior and obtain their input in making decisions. They also furnish a venue for practicing many of the social skills needed to success, like communication skills, problem solving and conflict resolution (Senter, 2005)

As Nelsen et al., (2000) suggests an effective way to build social skills, is by trying to remove the normal barriers to relationships and replace them with builders of relationships. Barriers are behaviors that prevent good relationships because they are disrespectful and discouraging to students, whereas builders are behaviors that build good relationships because they are encouraging (Nelsen et al., 2000; Charles, 2005). In their theory Nelsen et al., (2000), presented some examples of barriers versus builders, and they were: assuming versus checking, rescuing versus exploring, directing versus inviting/encouraging, expecting versus celebrating, and "adult-isms" versus respecting, and 
each of them is explained in a practical way, on how to be implemented within the program, in order for the intervention to be done successfully. Nelsen, Lott and Glenn (1993) state: "We guarantee 100\% improvement in student-teacher relationships when teachers simply learn to recognize barrier behaviors and stop demonstrating them. Where else can you get such a generous return for ceasing a behavior? And when the builders are added, the payoff is even greater (p.18)".

One of the biggest strengths that the Positive Discipline approach has, is that is not a highly structured discipline and teachers who use it can adapt it to their needs and realities, so they can also implement their personal style of teaching (Nelsen et al, 2000). Studies have shown that this approach is very successful when implemented well, especially when the intervention is made early, parents and teachers have joined the intervention groups and the class meeting session are respected precisely.

\section{References}

Battistich.V., (1999), "Assessing Implementation of the Child Development Project" Pennsylvania State University.

Browning, L; Davis, B; Resta.V, (2000) "What do you mean "think before I act? Conflict resolution with choices", Journal of Research in Childhood Education. Vol. 14(2).

Campbell.S., (1995), "Behavior problems in Preschool Children: A Review of Recent Research", Journal of Child Psychology Psychiatry.

Charles.C.M, Senter.G.W, (2005), "Building classroom discipline: Overview of Nelsen, Lott and Glenn's model", Pearson.

Elliott, Stephen P. (1993) "Caring to Learn: A Report on the Positive Impact of a Social Curriculum. Evaluation Report for the Responsive Classroom", Northeast Foundation for Children, Greenfield, MA.

Emmet.J.D, Monsour.F, Lundeberg.M, Russo.TmSecrist.K, Lindquist.N, Moriarity.S, Uhren.P, (1996), "Open Classroom meetings promoting peaceful schools", Elementary School Guidance and Counseling.

Glenn.H, Nelsen.J, (2000), "Raising self-reliant children in a self-indulgent world: Seven building blocks for developing capable young people", Roseville, CA: Prima.

Goodson.B.D, Layzer.J.I, St.Pierre.R, Robert.G, Bernstein.L.S, Lopez.M, (2001), "Effectiveness of a comprehensive, five-year family support program for low-income children and their families: Findings from the comprehensive child development program", Early Childhood Research Quarterly.

Hawkins.J.D, Catalano.R.F, Miller.J.Y, (1992), "Risk and protective factors for alcohol and other drug problems in adolescence and early childhood: Implications for substance abuse prevention", Psychological Bulletin.

Kellam.SH.G, Ling.X, Merisca.R, Brown.C.H, lalongo.N, (1998), "The effect of the level of aggression in the first grade classroom on the course and malleability of aggressive behavior into middle school", Development and Psychopathology.

Luiselli.J.K, Putnam.R.F, Handler.M.W, Feinberg.A.B, (2005), "Effects on student discipline problems and academic performance", The May Institute and the May Center for Applied Research, USA.

McVittie.J, (2003), "Research supporting Positive Discipline in home schools and communities", Positive Discipline Association.

McVittie.J, Chadsey.T (2006), " The Positive Discipline School", Positive Discipline Association.

Nelsen, Jane W. (1979), "The Effectiveness of Adlerian Parent and Teacher Study Groups in Changing Child Maladaptive Behavior in a Positive Direction", The University of San Francisco,

Nelsen.J, Lott.L, (2000), "Positive discipline for teenagers: Empowering your teens and yourself through kind and firm parenting", Roseville, CA: Prima.

Nelsen.J, Lott.L, Glenn.H, (1993) "Positive Discipline in the classroom", Rocklin, CA: Prima. Revised editions 1997, 2000.

Platt, Ann R. (1979), "Efficacy of Class Meetings in Elementary Schools", California State University, Sacramento.

Potter.Sh, (1999), "Positive Interaction among Fifth Graders: Is it a Possibility? The Effects of Classroom Meetings on Fifth -Grade Student Behavior", Southwest Texas State University, San Marcos, Texas.

Stanley.Sh.F, (1978), "Family education to enhance the moral atmosphere of the family and the moral development of adolescents", Journal of Counseling Psychology.

Weissberg.R.P, Greenberg.M.T, (1997), "Finding, evaluating, refining and applying empirically supported treatments for children and adolescents", Journal of Clinical Child Psychology.

Zeeman.R, Martucci.I, (1976), "The Application of Classroom Meetings to Special Education", Exceptional Children. 